\title{
Air pollution of beauty salons by cosmetics from the analysis of suspensed particulate matter
}

\author{
Patrycja Rogula-Kopiec ${ }^{1}$ Wioletta Rogula-Kozłowska ${ }^{1,2}\left(\mathbb{D} \cdot\right.$ Józef S. Pastuszka $^{3} \cdot$ Barbara Mathews $^{1}$
}

Received: 9 August 2017 / Accepted: 1 September 2018 / Published online: 11 September 2018

(c) The Author(s) 2018

\begin{abstract}
Beauty salons make a considerable part of the service sector. However, although the beauty salon staffs are exposed to a vast number of ambient chemicals during the whole workday, the occupational health hazard and the indoor air quality in beauty salons are poorly known. Specifically, reports on relations between indoor particulate matter and its outdoor or indoor sources in beauty salons are rare. Here we studied the effects of external and internal sources of aerosol in beauty salons on indoor ambient particulate matter and on its elemental and organic carbon contents. We selected four beauty salons differing in the number and type of particulate matter indoor and outdoor sources. The approach consisted in taking ten eight-hour samples of total suspended particulate matter and ten samples of its respirable sub-fraction simultaneously indoors and outdoors at each site, then analyzing them for carbon content using a thermo-optical method. The ambient concentrations of particulate matter and organic carbon were higher indoors than outdoors. We show that differences between indoor and the outdoor concentrations is due to the indoor use of cosmetics and other human activity. The effects of indoor sources on indoor elemental carbon concentrations are lower than on organic carbon concentrations.
\end{abstract}

Keywords Respirable particles $\cdot$ Indoor air $\cdot \mathrm{I} / \mathrm{O}$ ratio $\cdot$ Organic compounds $\cdot$ Elemental carbon $\cdot$ Pedicure $\cdot$ Manicure

\section{Introduction}

Ambient particulate matter (PM) is a priority air pollutant. The hazard to humans from inhaling PM is considered a serious issue, handled in general by reducing the emissions of PM and gaseous PM precursors in order to keep PM concentrations under permissible limits (EC 2008; WHO 2005; Mukherjee and Agrawal 2017, 2018). The limits exist for $\mathrm{PM}_{10}$ and $\mathrm{PM}_{2.5}\left(\mathrm{PM}_{\mathrm{x}}\right.$ - particles with the aerodynamic diameter not greater than $\mathrm{x} \mu \mathrm{m}$ ) in the atmospheric (outdoor) air and for total particulate matter (TPM) and $\mathrm{PM}_{4}$ in the air at some workplaces (indoors) (WHO 2010; Mukherjee and Agrawal 2017). However, although the most pervasive

Wioletta Rogula-Kozłowska

wioletta@ipis.zabrze.pl; wrogula@sgsp.edu.pl

1 Institute of Environmental Engineering, Polish Academy of Sciences, 34 M. Skłodowska-Curie St., 41-819 Zabrze, Poland

2 Faculty of Fire Safety Engineering, The Main School of Fire Service, 52/54 Słowackiego St., 01-629 Warsaw, Poland

3 Department of Air Protection, Silesian University of Technology, 22B Konarskiego St., 44-100 Gliwice, Poland exposure of humans to air pollution is that at the workplace (greater part of the human population, $8 \mathrm{~h}$ per day and human), many workplaces are not considered especially hazardous even when they are located within polluted areas, where outdoor pollutants, such as PM, add to those coming from indoor sources. Many service facilities in the Upper Silesia Agglomeration, Poland, are situated just in such circumstances, and beauty shops are among them. The indoor concentrations of TPM, $\mathrm{PM}_{4}$, and of some substances bound to them are the subject of the present work.

The Upper Silesia Agglomeration in southern Poland is a conglomerate of 14 highly industrialized cities and is one of the most PM-polluted European regions, with very high fine PM concentrations (Pastuszka et al. 2010; RogulaKozłowska 2014; Rogula-Kozłowska et al. 2014). More than $60 \%$ of its 2 million population are employed in the service sector and a great part of it [in general women; (stat.gov. $\mathrm{pl} /$ )] in the cosmetic and beauty treatment subsector, whose importance to the region economy grows. In cosmetic and beauty salons, the specific indoor activities and the use of various chemicals are supposed to greatly contribute organic carbon (OC) to the normal indoor levels of the organic air pollutants maintained by fine PM-bound carbon coming 
from outdoors (Mounier-Geyssant et al. 2006; Cosmetic Ingredient Review 2008; Tsigonia et al. 2010; Pak et al. 2013; Arezes et al. 2014; de Gennaro et al. 2014; Mancini et al. 2017). Such facilities, usually small shops located on the ground floors of buildings in populated city quarters, are numerous in the Agglomeration, and in every European city, too. The ambient (outdoor) concentrations of very fine particles of elemental carbon (EC) are usually elevated at such locations (Pant and Harrison 2013; Rogula-Kozłowska 2014, 2015; Atkinson et al. 2016), and the EC indoor concentrations are yet higher because of the EC accumulation indoors.

The goal of the work was to provide the evidence for the effects of the emissions from the specific activities and use of cosmetics on the concentrations and the structure of indoor PM and PM-bound carbon in beauty salons. The presented study is unique in that it concerns air pollution in a very specific workplace environment. The authors do not know any other works concerning air contamination with PM-bound carbon in beauty salons.

\section{Experimental}

Four beauty salon rooms (Salons 1, 2, 3, and 4) were selected in Bytom, a city within the Agglomeration (170,000 population, area of $69 \mathrm{~km}^{2}$ ). Two of them, Salons 2 and 3, were located in the very center of Bytom, on the high ground floor (3 $\mathrm{m}$ above street level) in the same residential building adapted to provide cosmetic services (five rooms, different services in different rooms). The rooms were of the size of about $18 \mathrm{~m}^{2}$ each; Salon 2 was a hairdresser's (haircut, dyeing, styling, spa, etc.), and Salon 3 was a nail care studio (pedicure, manicure, nail extension, and design). There were two worksites in each room, active all the day, and PM samplers were installed between them, no more than $2 \mathrm{~m}$ away from each. The rooms had only natural ventilation and were aired by opening the windows (made from polyvinyl chloride; material known as cellular PVC) only after 6 p.m., when the work was over; the windows were closed during the rest of the day. The doors of Salons 2 and 3 opened and closed each time a customer or worker entered or left the rooms, but no atmospheric air got inside, and the exchange of the air through the doors occurred only between the rooms and the hall which was common to both salons.

The two other rooms, Salons 1 and 4, were arranged in strip malls as single-room beauty salons. The strip mall containing Salon 4 was located in the middle of a living quarter, beyond the direct effects of road traffic, and was surrounded by blocks of flats, children's playgrounds, and lawns; the one with Salon 1 was located at the quarter edge, near to one of the most busy roads in Bytom. There were two hairdressing and one nail care worksites in each room. Each room had the floor area of about $35 \mathrm{~m}^{2}$. The ventilation, windows, airing, and the installation of the PM samplers were similar to those in Salons 2 and 3, but each opening-closing of the Salons 1 and 4 doors resulted in outdoors-indoors exchange of air, and this was an important difference between the two pairs of salons.

None of the selected beauty salons were directly affected by emissions from power stations, industry, etc.; only Salon 1 was directly and strongly affected by emissions from heavy road traffic. Although located in the city center, Salons 2, 3 , and 4 were distant from heavily trafficked arteries and crossroads. However, indirect effects of vehicular, industrial, or municipal emissions could not have been excluded at any of the sites (Pastuszka et al. 2010; Rogula-Kozłowska 2014, 2015; Rogula-Kozłowska et al. 2014).

Summer was selected for carrying out the measurements to avoid PM and PM-bound carbon emissions from coal and biomass combustion for heating, which in a heating season are very high in the whole Agglomeration and drown emissions from other sources out (Rogula-Kozłowska et al. 2014). Therefore, the customer traffic in the salons was low and not all worksites were active during the measuring periods. Every worksite was capable of serving 1-2 customers per hour (4-7 customers per day). Usually, in Salons 2 and 3 , during a single shift (10 am-6 pm), there were present a hairdresser, cosmetician, one being served, and, possibly, one waiting customer. In Salons 1 and 4, one hairdresser, one cosmetician, 2 served, and 1 or 2 waiting customers were usually present.

PM was collected on Whatman quartz fiber filters (QMA, $\varnothing 25$ mm; GE Medical Systems, Life Sciences, Warsaw, Poland) using Gilian Plus sampling pumps (Sensidyne, St. Petersburg, FL). TPM was sampled at the air flow of $2.0 \mathrm{~L} /$ min using a head without a coarse particle pre-separator, and $\mathrm{PM}_{4}$ was sampled at $2.2 \mathrm{~L} / \mathrm{min}$ using a head equipped with a micro-cyclone. Four pumps were used at each site simultaneously: two for collecting $\mathrm{PM}_{4}$ and TPM indoors, two other-outdoors. The outdoor pair was located in the opposite building, on the balcony or terrace just opposite to the salon windows, no more than $35 \mathrm{~m}$ away from the indoor pair and at approximately the same level above the street. One measurement consisted of an 8-h continuous PM sample taking with the simultaneous use of all four pumps. Between July 7 and August 29, 2015, at each beauty salon, ten such measurements were done: at Salon 1 in 07-18.07, at Salons 2 and 3 in 21.07-01.08, at Salon 4 in 08.08-29.08, not necessarily on consecutive days, usually from 10 a.m. to 6 p.m. during the salon opening hours. The outdoor pump pairs at Salons 2 and 3 were about $25 \mathrm{~m}$ away from each other.

The mass of a PM sample was determined by weighing the filter on a microbalance (Radwag; Radom, Poland, resolution of $1 \mu \mathrm{g}$ ) before and after the exposure. Before each weighing, the filter was conditioned in the weighing room 
for $48 \mathrm{~h}$ under stable conditions (humidity of $45 \pm 5 \%$ and air temperature of $20 \pm 2{ }^{\circ} \mathrm{C}$ ). After the PM mass determinations, a $1.5 \mathrm{~cm}^{2}$ fragment was cut out from each exposed filter and then the PM collected on it was analyzed for $\mathrm{PM}_{4}$ and TPM-bound organic and elemental carbon (respectively, $\mathrm{PM}_{4}$-bound $\mathrm{OC}$, TPM-bound $\mathrm{OC}, \mathrm{PM}_{4}$-bound EC, and TPM-bound EC) using a thermal-optical method (Lab OC-EC Aerosol Analyzer, Sunset Laboratories Inc.; Portland, OR, USA; EUSAAR-2 protocol). For OC determinations, the used protocol requires heating a PM sample in four temperatures, each maintained for some definite time (OC1 thermal fraction: $200{ }^{\circ} \mathrm{C}$ and 120 ; OC2: $300{ }^{\circ} \mathrm{C}$ and $150 \mathrm{~s}, \mathrm{OC} 3: 450{ }^{\circ} \mathrm{C}$ and $180 \mathrm{~s}, \mathrm{OC} 4: 650^{\circ} \mathrm{C}$ and $180 \mathrm{~s}$ ). For $\mathrm{EC}$ determinations it requires four-stage burning of a PM sample in oxygen (EC1 thermal fraction: $500^{\circ} \mathrm{C}$ and $120 \mathrm{~s}$; EC2: $550{ }^{\circ} \mathrm{C}$ and $120 \mathrm{~s} ; \mathrm{EC} 3: 700{ }^{\circ} \mathrm{C}$ and $70 \mathrm{~s} ; \mathrm{EC} 4: 850{ }^{\circ} \mathrm{C}$ and $80 \mathrm{~s})$. During the inert mode of the analysis, the fifth fraction (Pyr, pyrolytic carbon) of OC arises (Cavalli et al. 2010). The mass of the pyrolytic carbon is distributed among the OC1-OC4 masses by the analyzer software. Systematic calibration of the analyzer within the range proper for the determined concentrations and analyses of standards containing certified carbon contents (RM 8785 and RM 8786, NIST, Gaithersburg, MD, USA) and of blank samples were done to control the measurement performance. The detection limit for total carbon (TC), computed after analyzing the 26 blanks, was $0.52 \mu \mathrm{gC} / \mathrm{cm}^{2}\left(0.43\right.$ and $0.09 \mu \mathrm{gC} / \mathrm{cm}^{2}$ for $\mathrm{OC}$ and $\mathrm{EC}$, respectively). The standard recovery was from 98 to $122 \%$ of the certified value for OC and from 95 to $116 \%$ for EC. (The certified values were taken from the IMPROVE program.)

\section{Results and discussion}

Ambient organic carbon (OC) comes from the combustion of materials containing carbon, in southern Poland mainly from combustion of fossil fuels and biomass (Rogula-Kozłowska et al. 2014; Rogula-Kozłowska 2014, 2015). The amount of PM-bound OC in the air depends on these emissions and on the amounts and rate of formation of secondary organic carbon in the air (Castro et al. 1999). Ambient elemental carbon (EC) comes from incomplete combustion of materials containing carbon; in southern Poland, in spring and summer, PM-bound EC comes mainly from car exhaust emissions (Rogula-Kozłowska et al. 2014; Rogula-Kozłowska 2014, 2015). Indoor PM-bound organic and elemental carbon comes from outdoor air or indoor sources (Gupta and Bhandari 2011; Xu et al. 2015; Rogula-Kozłowska et al. 2017).

All selected beauty salons were equally affected by PM sources typical of residential areas, and Salon 1, additionally, by heavy road traffic. Salons 2 and 3 were in the same building and of the same size, they shared the hall and ventilation system, and they were two times smaller than Salons 1 and 4, which also were of the same size.

Despite similarity of the mechanisms of the inside/outside exchange of the air in Salons 1 and 4 or in Salons 2 and 3, the indoor/outdoor proportions of the PM-bound EC differed between Salons 1 and 4 and were almost the same at Salons 2 and 3; they were smallest at Salon 1 and greatest at Salon 4 (Table 1). At Salon 1, the concentrations of the road traffic emission marker, PM-bound EC (Pant and Harrison 2013; Rogula-Kozłowska 2014, 2015; Atkinson et al. 2016), both outdoors and indoors, were highest. There were no indoor PM-bound EC sources in Salon 1; its high indoor level was due to the accumulation of outdoor PM-bound EC. At Salon 4, where burning of scented candles and incense sticks (almost all the time during opening hours) was an effective indoor source of PM and PM-bound EC (Knight et al. 2001; Gupta and Bhandari 2011; Manoukian et al. 2013; Kumar et al. 2014; Zhou et al. 2015, 2016; Goel et al. 2017), the PM-bound EC originating from indoor sources prevailed over that from outdoors. This made the differences between the indoor and outdoor 8-h concentrations for both $\mathrm{PM}_{4}$-bound EC and TPM-bound EC statistically significant (Table 1). Scented candles and incense sticks were also used in Salon 3, where they were one of the causes of the correlations between the 8-h indoor concentrations of PM-bound OC and EC (Pearson correlation coefficient $r \geq 0.6$ ); none of these four correlations occurred at any other site.

In an urban area such as Bytom, even in beauty salons where there exists an indoor PM-bound EC source, the outdoor PM-bound EC visibly contributes to the indoor one. The effect is clearer in salons where direct indoor/outdoor air exchange through the doors is possible, like at Salons 1 and 4 , and especially when they are situated near an outdoor PM-bound EC source, like Salon 1.

Very high indoor PM-bound OC concentrations occurred equally in all the salons (Table 1). The vast differences between the mean indoor and outdoor concentrations of both $\mathrm{PM}_{4}$-bound OC and TPM-bound OC (Table 1) and the lacking significance of the correlation between the indoor and outdoor concentrations of OC $(r<0.6)$ prove strong dependency of indoor OC concentrations on indoor sources.

Biological matter or cosmetics, such as filings of nails and hard nail gels, tiny hair snippets, epidermis, would contribute to OC bound to coarse PM (i.e., particles with the aerodynamic diameter greater than $4 \mu \mathrm{m}$; all concentrations related to coarse PM are calculated as the difference between the respective concentrations related with TPM and $\mathrm{PM}_{4}$ ). For example, in Salons 1 and 4, about $40 \%$ of PM-bound OC is in coarse particles. Surprisingly, in Salon 3, which is basically a nail treatment salon, it is only $20 \%$ (Table 1). The difference may be due to the differences in the character and size between Salon 3 and 
Table 1 Indoor and outdoor ambient concentrations of respirable $\left(\mathrm{PM}_{4}\right)$ and total particulate matter (TPM) and organic carbon $(\mathrm{OC})$ and elemental carbon (EC) bound to them at four beauty salons

\begin{tabular}{|c|c|c|c|c|}
\hline & \multicolumn{3}{|c|}{ Concentration (10-day mean \pm standard deviation; $\mu \mathrm{g} / \mathrm{m}^{3}$ ) } & \multirow[t]{2}{*}{ Indoor/outdoor* } \\
\hline & & Indoor & Outdoor & \\
\hline \multirow[t]{6}{*}{ Beauty salon 1} & $\mathrm{PM}_{4}$ & $156.8 \pm 68.5$ & $105.0 \pm 94.7$ & $2.2 \pm 1.6^{* *}$ \\
\hline & TPM & $277.5 \pm 254.5$ & $147.1 \pm 114.0$ & $2.5 \pm 2.2 * *$ \\
\hline & $\mathrm{PM}_{4}$-bound OC & $77.3 \pm 31.2$ & $41.8 \pm 26.1$ & $2.6 \pm 2.1 * *$ \\
\hline & TPM-bound OC & $131.8 \pm 43.3$ & $68.4 \pm 50.9$ & $2.6 \pm 1.3^{* *}$ \\
\hline & $\mathrm{PM}_{4}$-bound EC & $3.8 \pm 2.6$ & $2.7 \pm 1.5$ & $1.8 \pm 1.8$ \\
\hline & TPM-bound EC & $6.6 \pm 3.5$ & $4.6 \pm 2.4$ & $1.7 \pm 1.2$ \\
\hline \multirow[t]{6}{*}{ Beauty salon 2} & $\mathrm{PM}_{4}$ & $118.1 \pm 76.2$ & $26.2 \pm 6.8$ & $4.8 \pm 3.7 * *$ \\
\hline & TPM & $185.5 \pm 130.4$ & $43.7 \pm 10.1$ & $4.7 \pm 3.4 * *$ \\
\hline & $\mathrm{PM}_{4}$-bound $\mathrm{OC}$ & $75.9 \pm 50.6$ & $15.6 \pm 5.1$ & $5.4 \pm 3.9 * *$ \\
\hline & TPM-bound OC & $86.4 \pm 52.6$ & $21.0 \pm 5.5$ & $4.5 \pm 2.8 * *$ \\
\hline & $\mathrm{PM}_{4}$-bound EC & $2.5 \pm 1.3$ & $1.7 \pm 0.3$ & $1.5 \pm 0.7$ \\
\hline & TPM-bound EC & $3.5 \pm 1.7$ & $3.0 \pm 0.7$ & $1.1 \pm 0.5$ \\
\hline \multirow[t]{6}{*}{ Beauty salon 3} & $\mathrm{PM}_{4}$ & $92.8 \pm 50.4$ & $24.8 \pm 5.8$ & $5.1 \pm 3.9 * *$ \\
\hline & TPM & $136.0 \pm 60.0$ & $43.7 \pm 10.1$ & $4.7 \pm 3.4 * *$ \\
\hline & $\mathrm{PM}_{4}$-bound $\mathrm{OC}$ & $58.0 \pm 24.8$ & $14.8 \pm 5.8$ & $5.7 \pm 4.0 * *$ \\
\hline & TPM-bound OC & $75.4 \pm 32.2$ & $20.3 \pm 3.8$ & $4.5 \pm 2.8^{* *}$ \\
\hline & $\mathrm{PM}_{4}$-bound EC & $3.1 \pm 2.5$ & $1.7 \pm 0.3$ & $1.4 \pm 0.7$ \\
\hline & TPM-bound EC & $4.7 \pm 3.0$ & $2.9 \pm 0.7$ & $1.1 \pm 0.5$ \\
\hline \multirow[t]{6}{*}{ Beauty salon 4} & $\mathrm{PM}_{4}$ & $170.2 \pm 72.8$ & $19.4 \pm 7.5$ & $9.6 \pm 5.1 * *$ \\
\hline & TPM & $272.5 \pm 128.7$ & $33.5 \pm 10.5$ & $9.0 \pm 5.7 * *$ \\
\hline & $\mathrm{PM}_{4}$-bound $\mathrm{OC}$ & $86.1 \pm 30.0$ & $10.5 \pm 2.5$ & $8.8 \pm 4.0^{* *}$ \\
\hline & TPM-bound OC & $164.6 \pm 78.3$ & $15.3 \pm 4.3$ & $12.0 \pm 7.2 * *$ \\
\hline & $\mathrm{PM}_{4}$-bound EC & $2.3 \pm 1.2$ & $0.8 \pm 0.5$ & $3.7 \pm 2.9 * *$ \\
\hline & TPM-bound EC & $4.3 \pm 2.7$ & $1.3 \pm 0.7$ & $4.3 \pm 3.7 * *$ \\
\hline
\end{tabular}

The 10-day mean concentrations of PM4, TPM, and bound to them carbon are greater indoors than outdoors at each Beauty Salon. However, while all other differences are statistically significant at each Beauty Salon, the indoor and outdoor concentrations for PM4- and TPM-bound EC statistically differ only at the least affected by road traffic Salon 4. At Salon 1, affected by traffic most, the PM4- and TPM-bound EC had the highest mean concentrations and the greatest daily variability both outdoors and indoors

*The mean of 10 proportions of indoor to outdoor concentration \pm standard deviation

**The differences between indoor and outdoor concentrations are statistically significant $(n=10$; MannWhitney $U$ test; $p=0.05$ )
Salons 1 and 4: the latter are bigger, and there are more workplaces in them, more staff and customer movement (e.g., from haircut chair to hair wash one) and more floor sweeping (because of hair cutting) that stir up and maintain the particles in the air. In small specialized salons, where there is much less of people's movement than in bigger multi-service ones, a great part of coarse PM-bound OC stays settled and fine PM-bound OC prevails in the air.

A great part of indoor PM-bound OC in beauty salons comes from using of a variety of cosmetics; they contain hydrocarbons, alcohols, esters, phenols, acids, etc. (Cosmetic Ingredient Review 2008; Nohynek et al. 2010; Rothe et al. 2011; Williams et al. 2016). Most of them are applied as aerosols directly from spray cans and bottles or atomizers. Some (hybrid) nail polishes, acrylics, and gels require
UV hardening; hair dyes and brighteners, various hair masks and conditioners are applied hot. Besides organic compounds, all used cosmetics and detergents contain also other substances, e.g., ammonia, which can react with indoor ambient organics (Cosmetic Ingredient Review 2008; Tsigonia et al. 2010; Pak et al. 2013; Madnani and Khan 2013; Arezes et al. 2014; de Gennaro et al. 2014; Aparecida da França et al. 2015; Mancini et al. 2017). Therefore, it is not surprising that $\mathrm{PM}_{4}$-bound $\mathrm{OC}$ made $60-80 \%$ of TPM-bound OC in average. Moreover, being inside, both coarse and fine PM particles, no matter if they come from outdoor or indoor sources, can be enriched in volatile or semi-volatile organic compounds, as it was already observed for polycyclic aromatic hydrocarbons 
and mercury in university teaching rooms (Majewski et al. 2016; Rogula-Kozłowska et al. 2017).

The differences between the indoor and outdoor behaviors of PM-bound carbon at the beauty salons can be clearly seen in the shares of EC and OC in total carbon $\mathrm{TC}(\mathrm{TC}=\mathrm{EC}+\mathrm{OC})$. The average shares of PM-bound OC in PM-bound TC were generally higher indoors than outdoors at each beauty salon (Fig. 1). The greatest differences occurred at Salons 2 and 3, the two salons smaller in size and with smaller crew than multi-service Salons 1 BS4. The less turbulent air together with significant gaseous chemical emissions from applied cosmetics (volatile organic compounds (VOC), ammonia, formaldehyde, ozone, etc.) in Salons 2 and 3 was favorable for the formation of secondary carbonaceous matter that bound later to fine PM (Ali et al. 2017). Through the Salons 2 and 3 common hall, the gaseous chemicals could easily migrate from one to another (e.g., ozone from ozone hair treatment in Salon 2 to Salon 3). The smallest differences between the indoor and outdoor means for $\mathrm{PM}_{4}$-bound $\mathrm{OC}$ and EC contents of TC, and the higher indoor than outdoor mean TPM-bound EC content of TC, occurred at Salon 1 (Fig. 1). This might have been the effect of rising the indoor EC to the level higher than in other salons by direct emissions of EC from the big road (Table 1), what, in turn, might have intensified the inhibition of the transformations of gaseous precursors of OC by absorbing sunlight or adsorbing volatile compounds. The indoor transformations of gaseous OC precursors seem to be more intense in the salons similar to Salons 2 and 3 than in salons such as Salons 1 and 4. The presence of a strong PMbound carbon source near a salon (like the big road at Salon 1 ) is also important to indoor and outdoor secondary OC

(a)

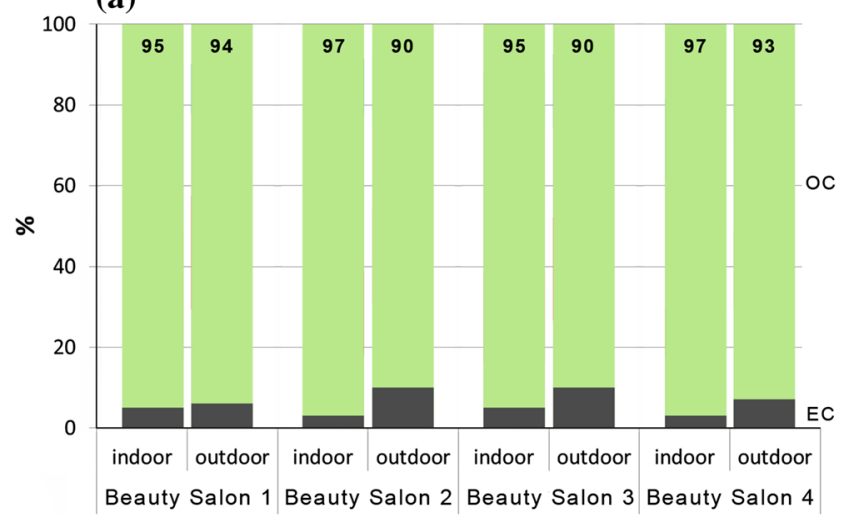

Fig. 1 Mean mass contributions (\%) of elemental (EC) and organic (OC) carbon to total carbon $(\mathrm{TC}$; $\mathrm{TC}=\mathrm{EC}+\mathrm{OC})$ in respirable $\left(\mathrm{PM}_{4}\right.$; a) and total (TPM; b) fractions of particulate matter in indoor and outdoor air of four beauty salons. The mass shares of EC in the indoor TC are lower than in the outdoor TC at the beauty salons beyond direct effects of road traffic (Salons 2-4) for both PM frac- formation. The explanation of such a distribution of the PMbound TC mass between OC and EC at the sampling sites is rather hard because, among other things, it should involve the evaluation of the amounts of secondary organic matter in the indoor air of the salons. However, the transformations of indoor VOCs can probably be one of the main factors of the formation of indoor PM-bound OC in the salons, just as it is in the atmosphere.

The two general patterns of distribution of TPM- and $\mathrm{PM}_{4}$-bound $\mathrm{OC}$ among the thermal fractions (arising during the PM thermal analysis) at the sites are presented in Fig. 2.

Their similarity to each other is probably due to the high mass contributions of $\mathrm{PM}_{4}$ and $\mathrm{PM}_{4}$-bound $\mathrm{OC}$ to TPM and TPM-bound OC, respectively (Table 1). Again, the differences between Salons 2 and 3 are very small for both TPM and $\mathrm{PM}_{4}$. Instead, at each site, the distributions of indoor and outdoor PM-bound $\mathrm{OC}$ are entirely different for both TPM and $\mathrm{PM}_{4}$.

The ambient secondary compounds arising from VOCs in photochemical reactions or from organic vapor condensation have relatively low molecular weights and boiling temperatures (Froines and Garabrant 1986; Cosmetic Ingredient Review 2008; Xu et al. 2015; Lachenmeier et al. 2017). During the analysis of PM for OC, they are released as $\mathrm{OC} 1$ at the temperature not exceeding $200{ }^{\circ} \mathrm{C}$ (Cavalli et al. 2010). Mean (in the measuring period) $\mathrm{OC} 1$ mass contribution to PM-bound OC was greater outdoors than indoors at all the sampling sites (Fig. 2). It does not mean that the penetration of secondary organic matter (quite adequately represented by $\mathrm{OC} 1$ outdoors) from the outside to the inside was not so efficient as that of primary matter-this only means that the remaining $\mathrm{OC}$ components were of greater importance

(b)

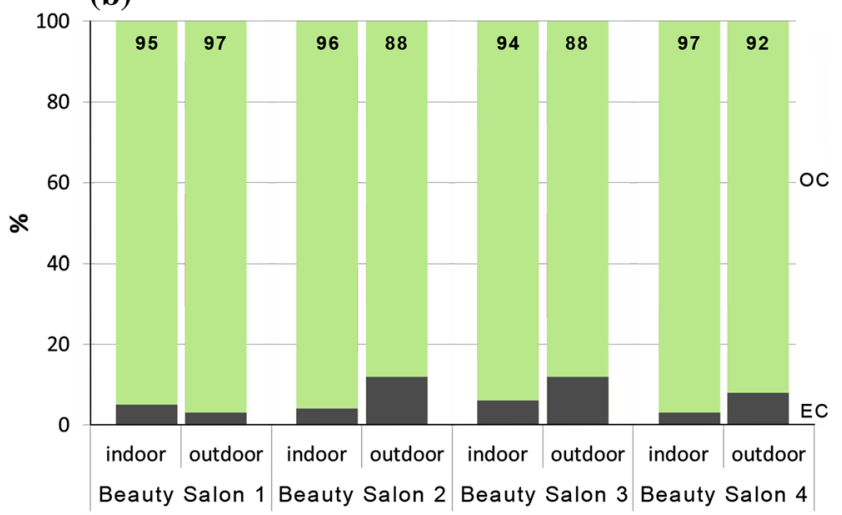

tions. At the beauty salon strongly affected by emissions from road traffic (Salon 1), only PM4-bound EC contributes less to the indoor TC and TPM-bound EC has relatively greater share in the indoor TC than in the outdoor one. At Salons 2 and 3, located in the same building, PM4- and TPM-bound EC shares in TC are almost equal, both indoors and outdoors; the same is true of the outdoor TC 
(a)

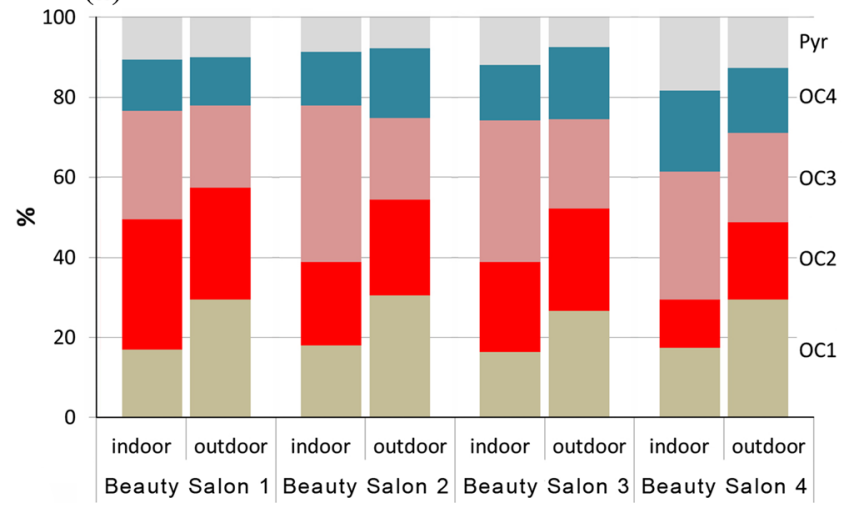

Fig. 2 Distributions of mean masses (\%) of OC bound to respirable $\left(\mathrm{PM}_{4}\right.$; a) and total (TPM; b) fractions of PM among thermal fractions of $\mathrm{OC}$ released during the analysis in the following temperatures (EUSAR-2 protocol): OC1: $200{ }^{\circ} \mathrm{C}, \mathrm{OC} 2: 300{ }^{\circ} \mathrm{C}$, OC3: $450{ }^{\circ} \mathrm{C}$, OC4: $650{ }^{\circ} \mathrm{C}$, and Pyr (pyrolytic carbon) that arises during the inert mode of the analysis (Cavalli et al. 2010). The fractions OC2 and OC3, consisting mostly of primary complex organic compounds boil-

indoors than outdoors at all sites. Inside the salons, besides secondary compounds, $\mathrm{OC} 1$ comprised also primary organic compounds, such as low boiling point alcohols (ethanol, lauryl alcohol), acids (salicylic), solvents (camphor), thickeners (bee wax) (Cosmetic Ingredient Review 2008; Williams et al. 2016; Lachenmeier et al. 2017). The thermal fractions OC2 and OC3 are dominant indoors at all the sites, and their contributions to OC outdoors are also significant. They contain quite complex organic compounds, and their boiling temperatures are between 300 and $650{ }^{\circ} \mathrm{C}$. Probably, they are the basic components of the cosmetics and chemicals used in the salons, such as glycerin, paraffin oil, vaseline, various polymers and copolymers (chitosan, collagen), salts (sodium laureth sulfate), acids (pantothenic and stearic) esters and diols (cetyl palmitate), proteins (keratin) (Cosmetic Ingredient Review 2008; Nohynek et al. 2010; Rothe et al. 2011; Williams et al. 2016; Lachenmeier et al. 2017). Although OC4 contents in PM-bound OC indoors and outdoors do not differ much at any site, it is rather clear that the OC4 composition indoors depends on the salon profile. Most probably, organic matter decomposed at $650{ }^{\circ} \mathrm{C}$ consists of cellulose and its derivatives coming from cosmetic fillers and thickeners and from biological matter (fragments of skin, nails, hair).

\section{Conclusions}

The mechanical treatment of hair and nails and the use of cosmetics in beauty salons exert much greater effects on the indoor concentrations of particulate matter (both fine and (b)

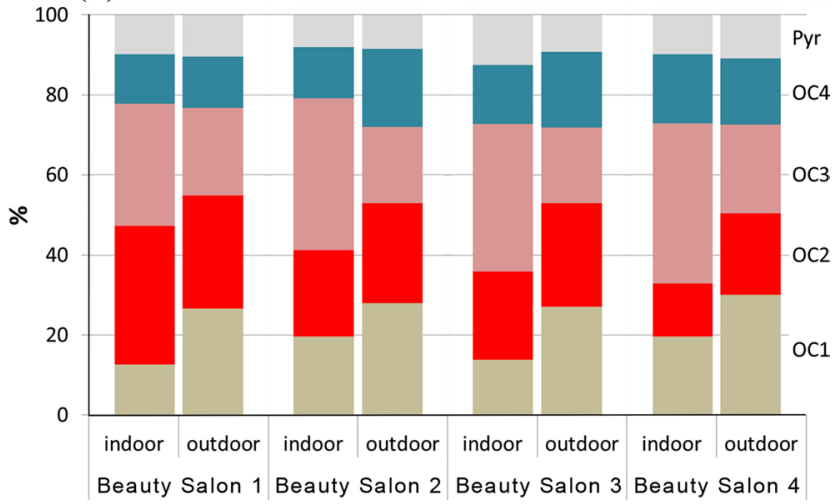

ing at $300-650^{\circ} \mathrm{C}$, are dominant indoors at all the beauty salons. Outdoors, secondary organic compounds prevail; they boil at no more than $200^{\circ} \mathrm{C}$ and come from transformations of primary and secondary gaseous and semi-volatile compounds. There exist clear outdoor/ indoor difference in mass distribution of PM bound OC among the thermal fraction

coarse), and on organic compounds bound to it as well, than outdoor air pollution. Depending on the experimental site, the mean $\mathrm{PM}_{4}$ - and TPM-bound organic carbon concentrations were 3-9 and 3-12 times, respectively, and mean $\mathrm{PM}_{4}$ and TPM ones 2-10 times greater indoors than outdoors. In contrary, the mean indoor concentrations of elemental carbon bound to particulate matter were almost equal to the means of the outdoor ones at all sites. The indoor 8-h concentrations of elemental carbon were visibly affected by its outdoor sources (mainly road traffic, no emissions from heating) in all salons; however, in two of them burning of scented candles and incense sticks, the only indoor elemental carbon source, caused significant statistical dependencies between 8-h indoor concentrations of elemental carbon and PM or organic carbon.

Although the paper provides strong evidence for the contribution of indoor sources of ambient carbon to PMbound carbon in beauty salons, it also signalizes the need for further investigations. To allow more precise conclusions concerning, for instance, setting indoor air quality standards for PM-bound substances in beauty salons, the measurement series should cover longer periods of time, maybe in various seasons of the year. The ways of the propagation of pollutants within the buildings and those of their indoor/ outdoor exchange should also be more closely considered. Such small beauty salons as those involved in the experiment outnumber big and better-equipped ones; however, the circumstances in the latter can be entirely different and they may have to be approached differently.

Anyway, the indoor aerosanitary conditions in the four investigated beauty salons are much worse than those 
outdoors. There exists a real health hazard from indoor PM and PM-bound carbon the workers of the beauty salons should be aware of and protected from. The use of some personal protective equipment, such as masks or respirators (containing sorbents), by the personnel is recommended, as well as air purification systems which would maintain some normed indoor/outdoor air exchange rates.

Acknowledgements The paper is based upon the results from the project (Grant) No. DEC-2013/09/N/ST10/04224 realized by the Institute of Environmental Engineering of Polish Academy of Sciences in Zabrze, and financed by the National Science Centre, Poland (NCN).

Open Access This article is distributed under the terms of the Creative Commons Attribution 4.0 International License (http://creativeco mmons.org/licenses/by/4.0/), which permits unrestricted use, distribution, and reproduction in any medium, provided you give appropriate credit to the original author(s) and the source, provide a link to the Creative Commons license, and indicate if changes were made.

\section{References}

Ali N, Ismail IMI, Khoder M, Shamy M, Alghamdi M, Khalaf AA, Costa M (2017) Polycyclic aromatic hydrocarbons (PAHs) in the settled dust of automobile workshops, health and carcinogenic risk evaluation. Sci Total Environ 601-602:478-484. https://doi. org/10.1016/j.scitotenv.2017.05.110

Aparecida da França S, Ferrera Dario M, Brigatto Esteves V, Rolim Baby A, Valéria M, Velasco R (2015) Types of hair dye and their mechanisms of action. Cosmetics 2:110-126. https://doi. org/10.3390/cosmetics2020110

Arezes P, Baptista JS, Barroso MP, Carneiro P, Cordeiro P, Nelson Costa N, Rui B, Melo RB, Sergio A, Miguel A, Perestrelo G (2014) Occupational safety and hygiene II. Taylor \& Francis Group, Abingdon

Atkinson RW, Analitis A, Samoli E, Fuller GW, Green DC, Mudway IS, Anderson HR, Kelly FJ (2016) Short-term exposure to trafficrelated air pollution and daily mortality in London, UK. J Exp Sci Environ Epidemiol 26:125-132. https://doi.org/10.1038/ jes. 2015.65

Castro LM, Pio CA, Harrison RM, Smith DJT (1999) Carbonaceous aerosol in urban and rural European atmospheres: estimation of secondary organic carbon concentrations. Atmos Environ 33(17):2771-2781. https://doi.org/10.1016/S1352-2310(98)00331 $-8$

Cavalli F, Viana M, Yttri KE, Genberg J, Putaud JP (2010) Toward a standardised thermal-optical protocol for measuring atmospheric organic and elemental carbon: the EUSAAR protocol. Atmos Meas Tech 3:79-89. https://doi.org/10.5194/amt-3-79-2010

Cosmetic Ingredient Review (2008) Final amended report on the safety assessment of methylparaben, ethylparaben, propylparaben, isopropylparaben, butylparaben, isobutylparabe, and benzylparaben as used in cosmetic products. Int J Toxicol 27(4):1. https://doi. org/10.1080/10915810802548359

EC (2008) Directive 2008/50/EC of the European Parliament and of the Council of 21 May 2008 on ambient air quality and cleaner air for Europe

Froines R, Garabrant DH (1986) Quantitative evaluation of manicurists exposure to methyl, ethyl and isobutyl methacrylates during production of synthetic fingernails. Appl Ind Hyg 1:70-74. https ://doi.org/10.1080/08828032.1986.10390471
Gennaro G, Gennaro L, Mazzone A, Porcelli F, Tutino M (2014) Indoor air quality in hair salons: screening of volatile organic compounds and indicators based on health risk assessment. Atmos Environ 83:119-126. https://doi.org/10.1016/j.atmosenv.2013.10.056

Goel A, Wathore R, Chakraborty T, Agrawal M (2017) Characteristics of exposure to particles due to incense burning inside temples in Kanpur, India. Aerosol Air Qual Res 17:608-615. https://doi. org/10.4209/aaqr.2016.04.0146

Gupta A, Bhandari M (2011) Monitoring and control of particulate matter in indoor air: a review. J Appl Nat Sci 3(1):139-150

Knight L, Levin A, Mendenhall C (2001) Candles and incense as potential sources of indoor air pollution: market analysis and literature review (EPA/600/R-01/001). U.S. Environmental Protection Agency, Washington

Kumar R, Gupta N, Kumar D, Mavi AK, Singh K, Kumarv M (2014) Monitoring of indoor particulate matter during burning of mosquito coil, incense sticks and dhoop. Indian J Allergy Asthma Immunol 28(2):68-73. https://doi.org/10.4103/0972-6691.140770

Lachenmeier DW, Mildau G, Rullmann A, Marx G, Walch SG, Hartwig A, Kuballa T (2017) Evaluation of mineral oil saturated hydrocarbons (MOSH) and mineral oil aromatic hydrocarbons (MOAH) in pure mineral hydrocarbon-based cosmetics and cosmetic raw materials using 1H NMR spectroscopy. F1000Research 6:682. https://doi.org/10.12688/f1000research.11534.2

Madnani N, Khan K (2013) Hair cosmetics. Indian J Dermatol Venereol Leprol 79(5):654-667

Majewski G, Kociszewska K, Rogula-Kozłowska W, Pyta H, RogulaKopiec P, Mucha W, Pastuszka JS (2016) Submicron particlebound mercury in university teaching rooms: a summer study from two Polish cities. Atmosphere 7:117. https://doi.org/10.3390/ atmos 7090117

Mancini L, Figliomeni M, Puccinelli C, Romanelli C, Volpi F, D’Angelo AM, Caciolli S, D’Ugo E, Volpi E, Giuseppetti R, Marcheggiani S (2017) A descriptive survey on microbiological risk in beauty salons. Microchem J. https://doi.org/10.1016/j. microc.2017.02.021

Manoukian A, Quivet E, Temime-Roussel B, Nicolas M, Maupetit F, Wortham H (2013) Emission characteristics of air pollutants from incense and candle burning in indoor atmospheres. Environ Sci Pollut Res 20(7):4659-4670. https://doi.org/10.1007/s1135 6-012-1394-y

Mounier-Geyssant E, Oury V, Mouchot L, Paris C, Zmirou-Navier D (2006) Exposure of hairdressing apprentices to airborne hazardous substances. Environ Health 5:23. https://doi. org/10.1186/1476-069X-5-23

Mukherjee A, Agrawal M (2017) World air particulate matter: sources, distribution and health effects. Environ Chem Lett 15:283-309. https://doi.org/10.1007/s10311-017-0611-9

Mukherjee A, Agrawal M (2018) Air pollutant levels are 12 times higher than guidelines in Varanasi, India. Sources and transfer. Environ Chem Lett 16:1009-1016. https://doi.org/10.1007/s1031 1-018-0706-y

Nohynek GJ, Antignac E, Re T, Toutain H (2010) Safety assessment of personal care products/cosmetics and their ingredients. Toxicol Appl Pharmacol 243:239-259. https://doi.org/10.1016/j. taap.2009.12.001

Pak VM, Powers M, Liu J (2013) Occupational chemical exposures among cosmetologists: risk of reproductive disorders. Workplace Health Saf 61(12):522-529. https://doi.org/10.1177/2165079913 06101204

Pant P, Harrison RM (2013) Estimation of the contribution of road traffic emissions to particulate matter concentrations from field measurements: a review. Atmos Environ 77:78-97. https://doi. org/10.1016/j.atmosenv.2013.04.028

Pastuszka JS, Rogula-Kozłowska W, Zajusz-Zubek E (2010) Characterization of PM10 and PM2.5 and associated heavy metals 
at the crossroads and urban background site in Zabrze, Upper Silesia, Poland, during the smog episodes. Environ Monit Assess 168(1-4):613-627. https://doi.org/10.1007/s10661-009-1138-8

Rogula-Kozłowska W (2014) Traffic-generated changes in the chemical characteristics of size-segregated urban aerosols. W Bull Environ Contam Toxicol 93:493-502. https://doi.org/10.1007/s0012 8-014-1364-9

Rogula-Kozłowska W (2015) Chemical composition and mass closure of ambient particulate matter at a crossroads and a highway in Katowice, Poland. Environ Prot Eng 41(2):15-29. https://doi. org/10.5277/epe 150202

Rogula-Kozłowska W, Klejnowski K, Rogula-Kopiec P, Ośródka L, Krajny E, Błaszczak B, Mathews B (2014) Spatial and seasonal variability of the mass concentration and chemical composition of PM2.5 in Poland. Air Qual Atmos Health 7:41-58. https://doi. org/10.1007/s11869-013-0222-y

Rogula-Kozłowska W, Kozielska B, Majewski G, Rogula-Kopiec P, Mucha W, Kociszewska K (2017) Submicron particle-bound polycyclic aromatic hydrocarbons in the Polish teaching rooms: concentrations, origin and health hazard. J Environ Sci. https:// doi.org/10.1016/j.jes.2017.06.022

Rothe H, Fautz R, Gerber E, Neumann L, Rettinger K, Schuhf W, Gronewold C (2011) Special aspects of cosmetic spray safety evaluations: principles on inhalation risk assessment. Toxicol Lett 205:97-104. https://doi.org/10.1016/j.toxlet.2011.05.1038

Tsigonia A, Lagoudi A, Chandrinou S, Linos A, Evlogias N, Alexopoulos EC (2010) Indoor air in beauty salons and occupational health exposure of cosmetologists to chemical substances. Int J Environ Res Public Health 7:314-324. https://doi.org/10.3390/ ijerph7010314
WHO (2005) Air quality guidelines-global update 2005. Geneva http://www.who.int/phe/health_topics/en/. Accessed 5 Aug 2017

WHO (2010) WHO guidelines for indoor air quality: selected pollutants. 2010. http://www.euro.who.int/en/health-topics/envir onment-and-health/air-quality/publications/2010/who-guidelines -for-indoor-air-quality-selected-pollutants. Accessed 5 Aug 2017

Williams FM, Rothe H, Barrett G, Chiodini A, Whyte J, Cronin MTD, Monteiro-Riviere NA, Plautz J, Roper C, Westerhout J, Yang Ch, Guy RH (2016) Assessing the safety of cosmetic chemicals: consideration of a flux decision tree to predict dermally delivered systemic dose for comparison with oral TTC (threshold of toxicological concern). Regul Toxicol Pharmacol 76:174-186. https ://doi.org/10.1016/j.yrtph.2016.01.005

Xu X, Guinot B, Shen Z, Ho KF, Niu X, Xiao S, Huang R-J, Cao $J$ (2015) Characteristics of organic and elemental carbon in $\mathrm{PM}_{2.5}$ and $\mathrm{PM}_{0.25}$ in indoor and outdoor environments of a middle school: secondary formation of organic carbon and sources identification. Atmosphere 6(3):361-379. https://doi.org/10.3390/ atmos6030361

Zhou R, An Q, Pan XW, Yang B, Hu J, Wang YH (2015) Higher cytotoxicity and genotoxicity of burning incense than cigarette. Environ Chem Lett 13:465-471. https://doi.org/10.1007/s1031 1-015-0521-7

Zhou R, Yang Y, Wang H (2016) Higher cytotoxicity and genotoxicity of cultivated versus natural agarwood incense smoke. Environ Chem Lett 14:501-506. https://doi.org/10.1007/s1031 1-016-0567-1 